a hemianopic from the good side, and many other simple but very worthwhile measures which can easily be put into practice by their attendants. The message to medical students and housemen is perhaps to become more personally involved in this aspect of patient care which is too often left entirely to physiotherapists and occupational therapists. With adequate rehabilitation 'the reward may be very rich even after an apparent catastrophe'.

\section{The Medical Management of the Surgical Patient}

By F. G. Smiddy. Pp. 280, hard cover. London: Edward Arnold, 1976. $£ 9.60$ (paper back $£ 4.75$ ).

An increasing task in the ever widening subject of therapeutics is the medical management of surgical patients in the pre- and post-operative period. Patients with increasingly complex respiratory, cardiac, metabolic and endocrine problems are being submitted to more and more extensive surgery and it is essential for the surgical staff to have up-todate information available. This excellent volume will fill a very considerable need. The author is a general surgeon of wide experience who, in a surprisingly short space, has packed an immense amount of information about the management of associated medical diseases (for example diabetes, cardiac problems and blood disorders), postoperative complications including fluid and electrolyte disturbances, deep vein thrombosis and post-operative intravenous feeding, the management of surgical infection, the use of antibiotics and cytotoxic drugs, pain relief, the treatment of multiple injuries and burns, the medical management of gastro-intestinal disease and the ancillary treatment of vascular and calculous disease. This volume can be recommended to surgeons at all levels who are daily concerned with these important and difficult therapeutic problems.

Modern Medicine (A textbook for students, practitioners and examiners by members of the teaching staff of the University of Bristol School of Medicine)

Edited by Alan E. ReaD, D. W. Barritt \& R. Langton

Hewer. Pp. 54.3, soft cover, illustrated. Tunbridge Wells,

Kent: Pitman Medical, 1975. $£ 8.00$

No-one will argue with the back cover statement that 'advances in medicine continue at an ever increasing rate and the medical student in his clinical course finds it difficult to get things in perspective'. This new textbook attempts to present the enormous number of facts generally assumed to be needed for those striving for the qualifying exams in a variety of ways. In the text there is a combination of explanatory exposition and of tabulated signs, symptoms, differential diagnosis, etc. On the whole this approach is highly successful. The extensive use of illustrations is less praiseworthy owing to the quality of the diagrams themselves which are unaesthetic and fussy, with captions in too small a print.

Each chapter has references for further reading but too many are to elderly original papers. We should not be asking today's medical students to be reading 20 -year-old papers on the use of anticoagulants in myocardial infarction. These should be well pruned and replaced by up-to-date reviews or monographs. The index also is inadequate with not enough cross references, which would greatly help to 'get things in perspective'. There are a number of factual errors, such as a statement that coeliac axis embolism causes gangrene of the gut; and also too many spelling mistakes--Paul-Bunnell comes off badly in a number of places.

The detailed presentation of a myriad of facts, that are only eventually acquired in the perspective the editors seek, after years of clinical practice, tends to hide the principles on which clinical medicine is based and by which the facts themselves can the more readily be learned. The traditional tabulation of diets is an example, albeit trivial, of this practice.
On the whole 'Modern Medicine' is a success without ڤొ quite living up to its name and without providing a radically different approach for a textbook of clinical medicine.

\section{Modern Trends in Cardiology-3}

Edited by M. F. Oliver. Pp. ix +519 , illustrated, hard $\stackrel{\overline{\vec{S}}}{\stackrel{9}{ }}$ cover. London: Butterworths, 1975. $£ 11.00$.

The theme of this volume is clearly ischaemic heart disease. The choice of subjects and authors has produced an eminently $\overline{\bar{C}}$ authoritative, readable and up-to-date account of the battle $\vec{\partial}$

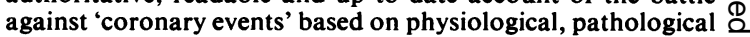
epidemiological and therapeutic considerations. There are sixteen articles, four of which deal with the cardiovascular $\infty$ system related to the nervous system (P. Sleight), catechol- $\overrightarrow{0}$ amines (A. M. Barrett and Roesmarie Einstein), prosta- glandins (E. W. Hortoff and A. Ungar), and insulin (E. A. $\vec{\omega}$ Nikkilä). The basis of arrhythmias in acute myocardial ischaemia (L. S. Gettes), and the antiarrhythmic drugs (D. E. Jewitt) combine nicely with the editor's article on his own special interest in the particular factors that lead, especially in cases of myocardial ischaemia, to sudden death. N There is also an informative article on the epidemiology of o sudden death) L.H. Kuller, J. A. Perper and M. D. Cooper). The myocardial basis of heart failure is dealt with in two articles by Winifred Nayler and A. H. Henderson, and non-invasive assessment of left ventricular function in man is very fully considered by $\mathrm{D}$. G. Gibson.

Beta-blockers in hypertension ( $J$. Conway) and a par- ticularly authoritative and illuminating account of hyper- $c$ lipidaemia (L. A. Carlson and A. G. Olsson) are of great practical importance, as is the well balanced review of aorta to coronary by-pass surgery for angina by D. G. Juliars There is a good review of the means available for measuring $\sigma$ total and regional myocardial blood flow (Maseri), and las but by no means least, a review of attempts made at pres venting ischaemic heart disease ( $Z$. Fejfar).

There are adequate references and a clear index. Even at $£ 11.00$ this volume represents excellent value for money. One's main quibble is perhaps that the title gives little indication of the well integrated account within the covers.

Refined Carbohydrate Foods and Disease-Some Implications of Dietary Fibre.

Edited by D. P. BukkitT and H. C. Trowell. Pp. Xv +

356, hard cover. London, New York, San Francisco:

Academic Press Inc. (London) Ltd, 1975. £7.50; \$19.25.

The past few years have brought a renewed interest in the aetiology of diseases which appear to be characteristic of our modern western civilization. The authors and their collaborators have collected and compared incidence patterns of non-infective disease between the western populations of Europe and North America and the developing populations of Africa and Asia. Evidence is presented which relates the geographical distribution and historical emergence of certain diseases to the dietary habits within these geographical confines. The diseases have been classified according to whether the maior causative factor is postulated to be deficiency of dietary fibre, the presence of fibre-depleted starch or the high consumption of refined sugar. Those diseases in the first group include appendicitis, diverticular disease, venous disorders and cancer of the colon, while those in the second and third groups include obesity, ischaemic heart disease and diabetes. The ideas and evidence are put forward clearly and concisely with many tables, diagrams and graphs. The book will be of wide interest to those involved in medical and nutritional research, dietetics and food technology. The authors, in their preface, have emphasized that some of their conclusions may have to be modified or even radically changed, but this book will stimulate further research which can only be of benefit to world health generally. 